\title{
Acquired Localized Diaphragmatic Eventration with Liver Herniation
}

\author{
Ryohei Ono, Hidehisa Takahashi, Daichi Yamashita and Kenichi Fukushima
}

Key words: diaphragmatic eventration, liver herniation, nodular opacity, liver scintigraphy, chest X-ray, imaging

(Intern Med 58: 1971-1972, 2019)

(DOI: 10.2169/internalmedicine.2150-18)
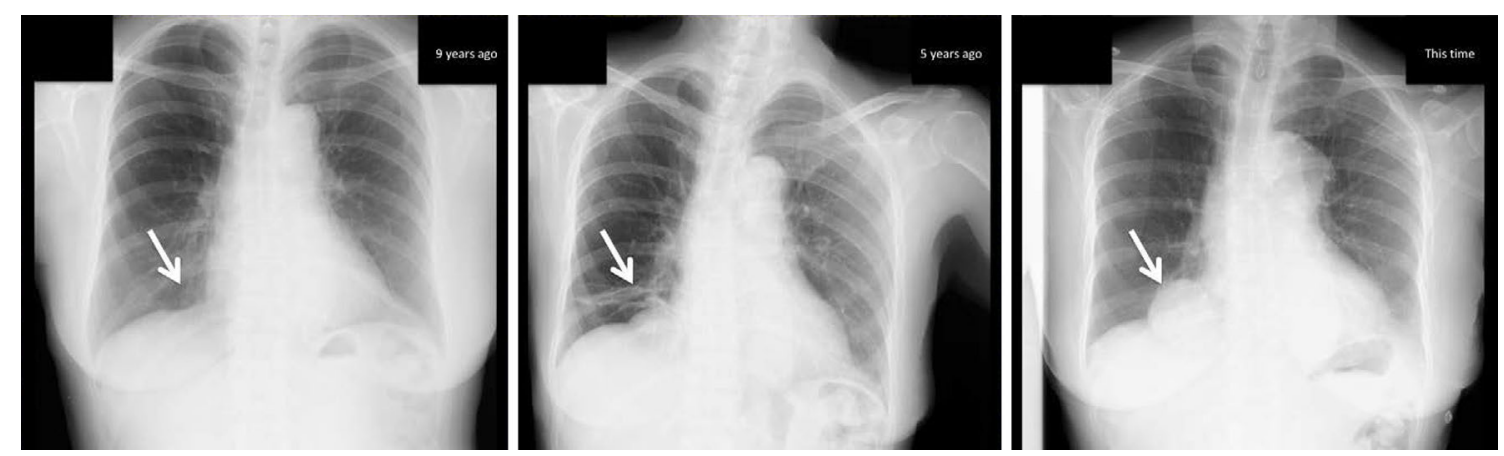

Picture 1.
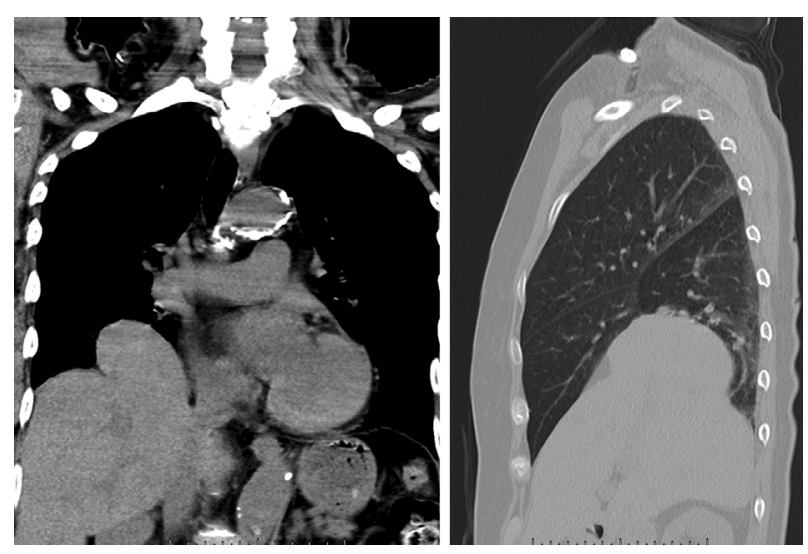

Picture 2.

A 77-year-old woman with no history of trauma was admitted with a recent myocardial infarction. A physical examination revealed no decreased breath sounds bilaterally. A routine chest X-ray showed an intrathoracic nodular opacity adjacent to the right diaphragm, which had increased in size in comparison to X-rays that had been taken 5 and 9 years preciously, respectively (Picture 1). Computed tomography

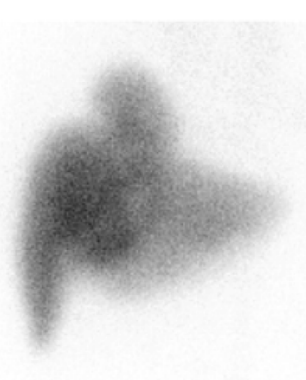

Picture 3.

of the chest revealed a localized diaphragmatic eventration with hepatic protrusion (Picture 2). ${ }^{99 \mathrm{~m}} \mathrm{Tc}$-galactosyl human serum albumin liver scintigraphy showed a focal elevation of the right lobe of the liver, and thus a diagnosis of liver herniation was made (Picture 3). Eventration of the diaphragm is caused by the development of weak fibrous diaphragmatic tissues. It is usually congenital, while the occurrence of acquired cases accompanied by trauma or increased intraabdominal pressure is rare (1). Liver herniation in association with such cases is relatively rare, but can sometimes be 
associated with diaphragmatic eventration when combined with compression of the diaphragm (2).

The authors state that they have no Conflict of Interest (COI).

\section{References}

1. Kansal AP, Chopra V, Chahal AS, Grover CS, Singh H, Kansal S.
Right-sided diaphragmatic eventration: a rare entity. Lung India 26: 48-50, 2009.

2. Ayane GN, Walsh M, Shifa J, Khutsafalo K. Right congenital diaphragmatic hernia associated with abnormality of the liver in adult. Pan Afr Med J 28: 70, 2017.

The Internal Medicine is an Open Access journal distributed under the Creative Commons Attribution-NonCommercial-NoDerivatives 4.0 International License. To view the details of this license, please visit (https://creativecommons.org/licenses/ by-nc-nd/4.0/).

\footnotetext{
(C) 2019 The Japanese Society of Internal Medicine Intern Med 58: 1971-1972, 2019
} 